\title{
Corrigendum
}

\section{VNS Therapy in Treatment-Resistant Depression: Clinical Evidence and Putative Neurobiological Mechanisms}

\author{
Charles B Nemeroff, Helen S Mayberg, Scott E Krahl, James McNamara, Alan Frazer, Thomas R Henry, \\ Mark S George, Dennis S Charney and Stephen K Brannan
}

Neuropsychopharmacology (2006) 3 I, 2329. doi: I 0. I038/sj.npp. I 30 I 190; published online 31 July 2006

Correction to: Neuropsychopharmacology (2006) 31, 1345-1355. doi.10.1038/sj.npp.1301082

In the above article, it was disclosed that the report was supported by an unrestricted educational grant from Cyberonics Inc. Of the nine authors, eight are academic researchers who are also consultants for Cyberonics Inc. Although the authors submitted appropriate disclosures in accordance to journal policy, that information was not included in the acknowledgement section of the published paper. The journal staff is reviewing procedures to avoid ambiguity concerning author financial disclosures. 